\title{
Carboxylic acid recovery from Fischer-Tropsch aqueous product by fractional freezing
}

\author{
Nuvaid Ahad $^{1} \cdot$ Arno de Klerk $^{1}$ (D) \\ Received: 16 June 2020 / Accepted: 10 September 2020 / Published online: 20 September 2020 \\ (c) The Author(s) 2020
}

\begin{abstract}
About half of the product from iron-based high-temperature Fischer-Tropsch synthesis is an aqueous product containing dissolved oxygenates. Volatile oxygenates can be recovered by distillation, but the bulk of the carboxylic acids remain in the water, which is called acid water. Fractional freezing was explored as a process for producing a more concentrated carboxylic acid solution from which the carboxylic acids could be recovered as petrochemical products, while concomitantly producing a cleaner wastewater. Solid-liquid equilibrium data were collected for aqueous solutions of acetic acid, propionic acid, and butyric acid. A synthetic Fischer-Tropsch acid water mixture ( $0.70 \mathrm{wt} \%$ acetic acid, $0.15 \mathrm{wt} \%$ propionic acid, and $0.15 \mathrm{wt} \%$ butyric acid) was prepared and the liquid phase concentrations of the acid species at solid-liquid equilibrium were determined. Control experiments with material balance closure on each of the carboxylic acid species were performed at selected conditions. Having more than one carboxylic acid species present in the mixture meaningfully changed the solid-liquid equilibrium versus temperature of the system. The carboxylic acids partitioned between the solid phase and the liquid phase and a practical design would require multiple duty-controlled solid-liquid equilibrium stages, with most of the separation taking place in the temperature range 0 to $-5^{\circ} \mathrm{C}$.
\end{abstract}

Keywords Acetic acid $\cdot$ Propionic acid $\cdot$ Butyric acid $\cdot$ Fischer-Tropsch aqueous product $\cdot$ Solid-liquid equilibrium

\section{Introduction}

Fischer-Tropsch synthesis is an industrially proven pathway for converting synthesis gas, i.e., $\mathrm{H}_{2}$ and $\mathrm{CO}$, to synthetic oil [11]. The synthetic oil is sulfur free and nitrogen free and consists of a mixture of paraffins, olefins, and oxygenates. The composition of the oil can be manipulated through the Fischer-Tropsch synthesis. This provides flexibility in application, making Fischer-Tropsch synthesis a useful process for both transport fuel and petrochemical production [5, 6].

When Fischer-Tropsch synthesis is applied to petrochemical production, the emphasis is on olefins and oxygenates, since these classes contain major commodity petrochemicals, ethylene, propylene, methanol, ethanol and acetic acid, among others. These petrochemicals are most abundant in the product from iron-catalyzed high-temperature Fischer-Tropsch synthesis. Of relevance to this work is the

Arno de Klerk

deklerk@ualberta.ca

1 Department of Chemical and Materials Engineering, University of Alberta, Edmonton, AB T6G 1H9, Canada carboxylic acids, which are recovered after Fischer-Tropsch synthesis as an aqueous phase product, also called 'reaction water'. By mass, the aqueous product is the major product from Fischer-Tropsch synthesis, around $0.55-0.60 \mathrm{~kg} / \mathrm{kg}$ synthesis gas converted.

The Fischer-Tropsch aqueous product contains a mixture of water-soluble oxygenates. These oxygenates are short carbon chain alcohols, aldehydes, ketones, and carboxylic acids. The composition of a typical high-temperature Fischer-Tropsch aqueous product is given in Table 1 [5].

Recovering the carboxylic acids is challenging due to the dilute nature of the acids in the aqueous product. Fischer-Tropsch synthesis produces almost no formic acid and the main carboxylic acids that are present in the aqueous product are acetic acid, propionic acid and butyric acid. The carboxylic acids all have boiling points higher than that of water, which makes direct recovery by distillation impractical due to the high associated energy consumption.

The water treatment methods employed industrially make use mainly of biological treatment, which may be preceded by distillation to recover volatile oxygenates [11]. Processes employing both anaerobic and aerobic treatment can be 
Table 1 Composition of a typical high-temperature Fischer-Tropsch aqueous product

\begin{tabular}{lll}
\hline Compounds & $\begin{array}{l}\text { Fraction in class } \\
(\mathrm{wt} / \mathrm{wt})\end{array}$ & $\begin{array}{l}\text { HTFT aqueous } \\
\text { product }(\mathrm{wt} \%)\end{array}$ \\
\hline Water & 1 & 92.8 \\
Alcohols $^{\mathrm{a}}$ & & \\
Methanol & 0.02 & \\
Ethanol & 0.66 & \\
Propanols & 0.19 & \\
Butanols & 0.11 & \\
Heavier alcohols & 0.02 & \\
$\Sigma$ & 1 & \\
Carbonyls & \\
Acetaldehyde & 0.15 & \\
Propionaldehyde & 0.05 & \\
Heavier aldehydes & 0.03 & \\
Acetone & 0.55 & \\
Butanone & 0.16 & \\
Heavier carbonyls & 0.06 & \\
$\Sigma$ & 1 & \\
Carboxylic acids & & \\
Acetic acid & 0.70 & \\
Propionic acid & 0.16 & \\
Butyric acid & 0.09 & \\
Heavier acids & 0.05 & \\
$\Sigma$ & 1 & \\
\hline
\end{tabular}

${ }^{a}$ The ratio of alcohols to carbonyl compounds is sensitive to the HTFT synthesis conditions, since secondary hydrogenation of carbonyls to alcohols can take place

found. Other non-biological processes to convert the carboxylic acids in Fischer-Tropsch aqueous product include, among others, wet oxidation [2], ozonation [10], Kolbe electrolysis [1], and aqueous phase reforming [4].
Recovery of the carboxylic acids from Fischer-Tropsch aqueous product by liquid-liquid extraction using methyl tert-butyl ether was technically successful [3], but it did not lead to an economically viable process. The reasons for this are explained in a technical analysis of liquid-liquid extraction processes to recover organic acids from dilute aqueous solution, which highlight the energy-intensive nature of most processes proposed in the literature [13].

A different approach that could be considered for separation is to make use of fractional freezing. Compared to the heat of vaporization of water, which is around $2260 \mathrm{~kJ} /$ $\mathrm{kg}$ for atmospheric distillation, the enthalpy of freezing is $330 \mathrm{~kJ} / \mathrm{kg}$ [12].

Fractional freezing was previously considered for petroleum refinery wastewater treatment [8] and for the separation of organic acids from wastewater [14], but it is not a process that was evaluated specifically for carboxylic acid recovery from Fischer-Tropsch aqueous product. To illustrate the proposed concept for carboxylic acid recovery from the Fischer-Tropsch aqueous product, a process flow diagram of high-temperature Fischer-Tropsch synthesis is shown in Fig. 1 and the description makes reference to the stream numbers in the flow diagram.

Synthesis gas (stream 1) enters the high-temperature Fischer-Tropsch reactor to be converted to a hot gas phase product (stream 2). The hot product is stepwise cooled down and the heaviest oil fraction is condensed in the first stage of cooling (stream 3). The decanted oil product (stream 4) is recovered as a hot liquid by phase separation. The uncondensed gaseous product (stream 5) is further cooled down to produce a three-phase product (stream 6). The three-phase product is phase separated into a gaseous product (stream 7), oil product (stream 8 ), and aqueous product (stream 9 ). The aqueous product contains a mixture of oxygenates dissolved in the water with a typical composition as listed in Table 1.
Fig. 1 Process flow diagram of the Fischer-Tropsch aqueous product treatment process showing acid water treatment by fractional freezing

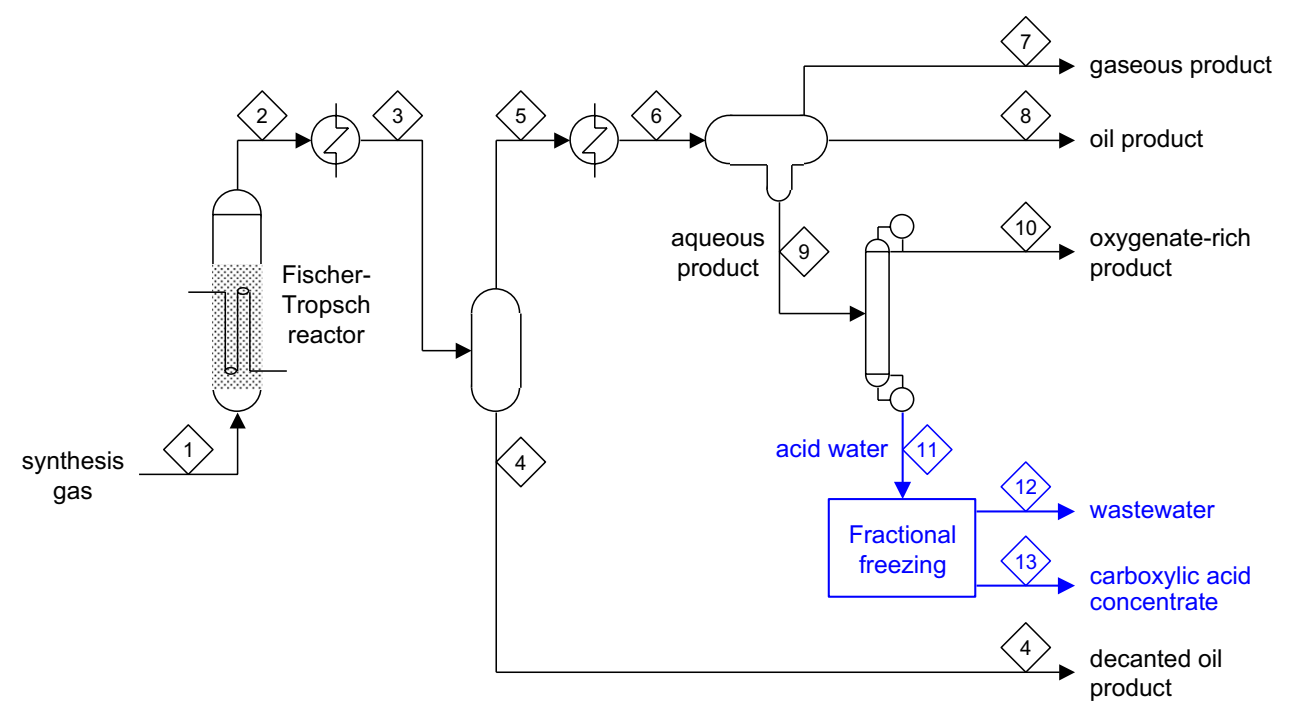


The lower boiling oxygenates can be recovered by distillation at near atmospheric pressure to produce an oxygenate-rich overhead product (stream 10). The oxygenaterich product is an oxygenate-water azeotrope that contains 20-25 wt\% water. The bottom product from distillation of the aqueous product is the acid water (stream 11). The acid water is a dilute mixture of mainly carboxylic acids in water, with a carboxylic acid concentration of around $1 \mathrm{wt} \%$, which serves as feed to the fractional freezing process investigated in this study. Fractional freezing is employed to separate the acid water into a wastewater with low organic content (stream 12) and a carboxylic acid concentrate (stream 13).

The carboxylic acids can be purified as individual petrochemical products from the carboxylic acid concentrate [15]. If the high-temperature Fischer-Tropsch process is employed mainly for transport fuel production, a 100,000 barrels per day Fischer-Tropsch refinery will co-produce 35-40 kt per year of acetic acid and 5-10 kt per year of propionic acid.

The experimental study comprised two parts. In the first part, solid-liquid equilibrium data were collected for aqueous solutions of acetic acid (ethanoic acid), propionic acid (propanoic acid), and butyric acid (butanoic acid). The experimental solid-liquid equilibrium data were compared with equilibrium data available in literature [7, 9]. In the second part, a synthetic mixture was prepared to represent the carboxylic acid distribution in Fischer-Tropsch acid water. The solid-liquid equilibrium data for this mixture was measured to determine a likely operating curve for the fractional freezing process shown in Fig. 1. Based on the outcome of the experimental work, the proposal was evaluated for potential further development.

The main contributions from this work are the experimental measurement of the solid-liquid equilibria of acetic, propionic, and butyric acid, as well as the application of fractional freezing as potential method for recovering these carboxylic acids from a Fischer-Tropsch aqueous product.

\section{Experimental}

\section{Materials}

The carboxylic acids used in the study were acetic acid $\left(\mathrm{C}_{2} \mathrm{H}_{4} \mathrm{O}_{2}, 99.7 \%\right)$, propionic acid $\left(\mathrm{C}_{3} \mathrm{H}_{6} \mathrm{O}_{2}, \geq 99.5 \%\right)$ and butyric acid $\left(\mathrm{C}_{4} \mathrm{H}_{8} \mathrm{O}_{2}, \geq 99 \%\right)$ that were purchased from Sigma Aldrich. Solutions were prepared in deionized water (conductivity around $3 \mu \mathrm{S} / \mathrm{cm}$ at $25{ }^{\circ} \mathrm{C}$ ) and obtained from a Milli-Q Millipore.

Some chemicals were also employed for analytical purposes. For titration, $1 \mathrm{M}$ standard solution of sodium hydroxide supplied by Sigma-Aldrich was used. Monosodium phosphate $\left(\mathrm{NaH}_{2} \mathrm{PO}_{4}, 99 \%\right)$ was used to prepare a buffer for high-performance liquid chromatography (HPLC) and was purchased from Fischer Scientific. Formic acid $\left(\mathrm{CH}_{2} \mathrm{O}_{2},>98 \%\right)$ employed in the HPLC analysis was obtained from Acros Organics.

\section{Equipment and procedure}

\section{Fractional freezing of individual acids}

For individual acids (acetic acid, propionic acid and butyric acid), $8.00 \mathrm{~g}$ of each acid was mixed with distilled water to prepare $800.00 \mathrm{~g}$ of a $1 \mathrm{wt} \%$ solution of each acid. The solutions were prepared gravimetrically using a Mettler Toledo MT ML3002E balance, with $3200 \mathrm{~g}$ capacity and $0.01 \mathrm{~g}$ readability.

The procedure followed to determine the solid-liquid equilibrium curve was the same for each of the carboxylic acids. For each acid, a $1 \mathrm{wt} \%$ solution of carboxylic acid was prepared in a $1000 \mathrm{~mL}$ Erlenmeyer flask. The $1000 \mathrm{~mL}$ flask was placed (submerged) in the chiller bath of a Julabo Scientific FP 50-MA, which is capable of maintaining the temperature to $0.02{ }^{\circ} \mathrm{C}$ within the temperature range -50 to $200^{\circ} \mathrm{C}$. The chiller was used to decrease the temperature of the acid solution in a stepwise fashion from room temperature to its eutectic point. The eutectic points reported by Faucon [7] were $-27{ }^{\circ} \mathrm{C}$ for acetic acid, $-29.4{ }^{\circ} \mathrm{C}$ for propionic acid and $-13.4{ }^{\circ} \mathrm{C}$ for butyric acid. The eutectic point for propionic acid reported by Htira et al. [9] was $-30{ }^{\circ} \mathrm{C}$. The intervals with which the temperature was decreased varied depending on the acid and its solid-liquid equilibrium response and temperature intervals were between -1 and $-5^{\circ} \mathrm{C}$.

As temperature was decreased to $0{ }^{\circ} \mathrm{C}$ and below, water in the solution started to freeze. The temperature was gradually decreased until more than half of the water in the solution froze. This was out of necessity a slow process, because it was necessary to avoid inclusion of acid in the ice due to too rapid freezing of the liquid phase of diminishing liquid volume. More than $24 \mathrm{~h}$ was allowed at each temperature to reach equilibrium. The concentrated solution left in the flask was separated from ice crystals and its acid concentration was determined by titration with $1 \mathrm{M} \mathrm{NaOH}$.

To avoid carryover of analytical errors, and to avoid dealing with a smaller volume of the liquid phase, a fresh solution of acid in water was prepared at the same concentration as the liquid phase at the solid-liquid equilibrium measurement point. The same procedure was repeated to determine the next solid-liquid equilibrium point. The only differences were that the starting temperature was the temperature at which equilibrium was obtained and that the acid solution had a different concentration, namely, the equilibrium concentration of the liquid phase.

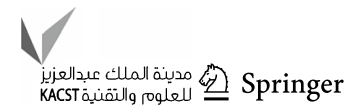




\section{Fractional freezing of synthetic acid water}

A synthetic acid water mixture was prepared to represent the carboxylic acid distribution in high-temperature Fischer-Tropsch acid water. The mixture consisted of $0.70 \mathrm{wt} \%$ acetic acid, $0.15 \mathrm{wt} \%$ propionic acid and $0.15 \mathrm{wt} \%$ butyric acid in deionized water.

For the purpose of determining the solid-liquid equilibrium at different temperatures, $800.00 \mathrm{~g}$ of this solution was prepared gravimetrically in a $1000 \mathrm{ml}$ Erlenmeyer flask. The solid-liquid equilibrium was determined at six different temperatures $(-1,-5,-10,-15,-20$ and $-25^{\circ} \mathrm{C}$ ). The same stepwise cooling procedure was applied to the synthetic acid water to determine the equilibrium composition as was used for individual acids. As in the case of the individual acids, the liquid phase was analyzed by titration with $1 \mathrm{M} \mathrm{NaOH}$ to quantify the total amount of acids. However, since this was a mixture of acids, a different analytical procedure had to be followed to quantify the individual acids. For the quantification of the acids in the liquid phase, analysis was performed using HPLC. A new $800.00 \mathrm{~g}$ solution was prepared based on the analysis of the liquid phase for the next temperature step. To be clear, the analysis of the liquid phase in solid-liquid equilibrium at $-1{ }^{\circ} \mathrm{C}$ was used as composition for further cooling to $-5^{\circ} \mathrm{C}$ and so forth.

\section{Practical control experiments at $-25^{\circ} \mathrm{C}$}

A practical concern when working with concentrated acid solutions at low temperature was that solid formation by freezing could encapsulate pockets of acidic liquid. In an industrial process, there would not be the luxury of time to engage in slow cooling as was performed for the solid-liquid equilibrium measurements. The fractional freezing experiments of the mixed acid solution also indicated that the solid phase that was formed was no longer just water, but a mixture of water and acids. Two practical control experiments were performed to assess the extent of acid inclusion in the solid phase.

This evaluation was performed for two different acid mixtures. The acid mixtures were prepared gravimetrically and the exact composition of each is reported as part of the results. Each mixture was $500.00 \mathrm{~g}$. The mixtures were cooled down to $-25{ }^{\circ} \mathrm{C}$ and allowed to freeze until around half of the solution was frozen. After separating the liquid phase from the solids, the solids were washed with a known quantity of ice cold distilled water to remove excess of acids on the solids, while trying to keep the extent of melting of the solid to a minimum. The liquid phase, the washed solids and the wash liquid were all weighed and subsequently analyzed by HPLC to determine the material balance.

\section{Analyses}

\section{Acid titration}

The concentration of the carboxylic acids in carboxylic acid aqueous solution was determined by titrating it against $1 \mathrm{M}$ standard sodium hydroxide with phenolphthalein as indicator. A glass burette (50 $\mathrm{ml}$ burette, $1 / 10 \mathrm{ml}$, A grade glass) from Kimax Kimble was used for performing titration.

\section{HPLC analysis}

For the mixture of carboxylic acids in water, the concentration of each acid in the water was determined by using a Waters 2695 HPLC system fitted with a Waters 2414 refractive index (RI) detector. A reverse phase column from Waters (Atlantis dC18 $4.6 \times 150 \mathrm{~mm}, 5 \mu \mathrm{m}$ ) with Waters VanGuard column guard was used in the HPLC and the column was operated at $30^{\circ} \mathrm{C}$. The sample injection volume was $10 \mu \mathrm{L}$. Sample analysis was completed within $40 \mathrm{~min}$. Data were recorded by using Waters Empower software. The peaks for the different acids were identified based on their retention times.

The mobile phase consisted of $20 \mathrm{mM} \mathrm{NaH}_{2} \mathrm{PO}_{4}$ and its $\mathrm{pH}$ was kept around 2.7 by adding formic acid. It was filtered through Millipore filter paper with $0.22 \mu \mathrm{m}$ pore size before being used in HPLC. An isocratic elution procedure was applied to the mobile phase with the flow rate of $0.5 \mathrm{~mL} /$ min.

Standard stock solution containing all the three acids was prepared in distilled water. Calibration solutions were prepared by dilution of the stock solutions with distilled water. A calibration curve based on the peak areas was developed by injecting calibration solutions in the HPLC using the same procedure of analysis. The concentration of each acid in the unknown samples was then calculated from the peak areas in relation to the peak areas obtained from the calibration.

It was found that column saturation occurred when there was about $15 \mathrm{wt} \%$ of each acid in the water. More concentrated acid solutions were diluted before HPLC analysis. The dilution was performed with deionized water by adding $200 \mu \mathrm{L}$ of sample to $1000 \mu \mathrm{L}$ of water and then injecting the diluted sample into the HPLC for analysis.

\section{Results}

\section{Solid-liquid equilibrium of acetic acid-water}

The objectives of determining the binary carboxylic acid and water solid-liquid equilibrium data were to verify that the experimental protocol worked and that the data were 
comparable to the solid-liquid equilibrium data in literature. It should be pointed out that the experimental approach taken was aligned with the intended application, namely, Fischer-Tropsch acid water treatment, rather than designed to be a rigorous thermodynamic data collection. Thus, if the protocol led to credible solid-liquid equilibrium data, confidence in the outcome of the applied study for which no literature data were available would be higher.

At a starting composition $1.0 \mathrm{wt} \%$ acetic acid and room temperature, the mixture remained in the liquid phase as it was cooled down to $0{ }^{\circ} \mathrm{C}$. At this point, water crystals start to form and the composition of the remaining liquid then becomes richer with acid. As heat was removed from the solution, more water crystals were formed and the crystallization temperature also decreased. The first solid-liquid equilibrium measurement point was at $-1.00 \pm 0.02{ }^{\circ} \mathrm{C}$. At this temperature point, the acid concentration in the liquid was $2.6 \mathrm{wt} \%$, with more than half of the water being frozen. As was explained in the Experimental section, a fresh solution was prepared with $2.6 \mathrm{wt} \%$ acetic acid, which was cooled down to $-5.00 \pm 0.02{ }^{\circ} \mathrm{C}$ to obtain the next solid-liquid equilibrium measurement point. The same process was repeated until the eutectic temperature was reached.

The experimental solid-liquid equilibrium measurements that were obtained in this manner are shown in Fig. 2, together with values from literature [7].

There was reasonable agreement between the experimentally determined acid concentrations at solid-liquid equilibrium and those from Faucon [7]. At the eutectic point $\left(-27^{\circ} \mathrm{C}\right)$, the acetic acid concentration in the liquid phase was $58.0 \mathrm{wt} \%$, compared to the literature value of $58.1 \mathrm{wt} \%$. It is not possible to make use of fractional freezing to increase the acetic acid concentration beyond the value at the eutectic point. Further cooling to decrease the temperature beyond the eutectic point will cause freezing of the total mixture.

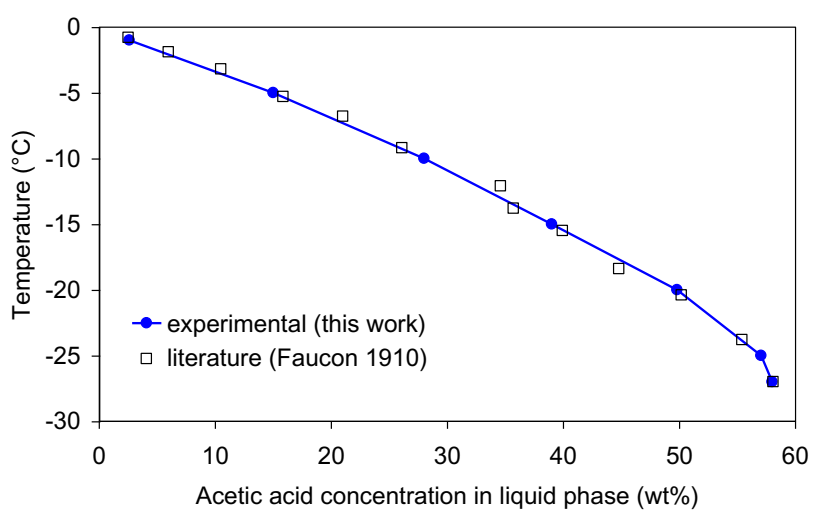

Fig. 2 Solid-liquid equilibrium concentration of acetic acid in water at different temperatures, showing experimental measurements (closed circle) and literature values (open square).

\section{Solid-liquid equilibrium of propionic acid-water}

The procedure employed for determining the propionic acid concentration in the liquid phase at solid-liquid equilibrium conditions was similar to that used for acetic acid. The solid-liquid equilibrium acid concentration measurements are shown in Fig. 3, and are compared with the values from literature $[7,9]$.

The experimentally determined data were in reasonable agreement with the data of Faucon [7] and Htira et al. [9] for the solid-liquid equilibrium of propionic acid and water. The values shown in Fig. 3 from the study by Htira, et al. [9] were those obtained using dynamic cooling and heating a of bulk solution at a rate of $1{ }^{\circ} \mathrm{C} / \mathrm{h}$. They also reported values determined by differential scanning calorimetry, which used the temperature at maximum energy flow found at different cooling rates to determine the temperature of solid-liquid equilibrium. A comparison of the two methods indicated that differential scanning calorimetry resulted in somewhat (about $1{ }^{\circ} \mathrm{C}$ ) lower temperature values.

At the eutectic point $\left(-29.4^{\circ} \mathrm{C}\right)$, the propionic acid concentration was $87.5 \mathrm{wt} \%$. The values reported in literature were $89 \%$ (Hitra et al. 2016) and 87.6 wt\% [7].

\section{Solid-liquid equilibrium of butyric acid-water}

The solid-liquid equilibrium data for butyric acid-water were collected in the same way as for acetic acid-water. The acid concentration in the liquid at equilibrium at different temperatures is shown in Fig. 4 and compared with literature data from Faucon [7].

There was reasonable agreement between the experimental data collected in this work and that reported by Faucon [7]. At the eutectic point $\left(-13.4{ }^{\circ} \mathrm{C}\right)$, the butyric acid concentration in the liquid phase was $87.2 \mathrm{wt} \%$, compared to

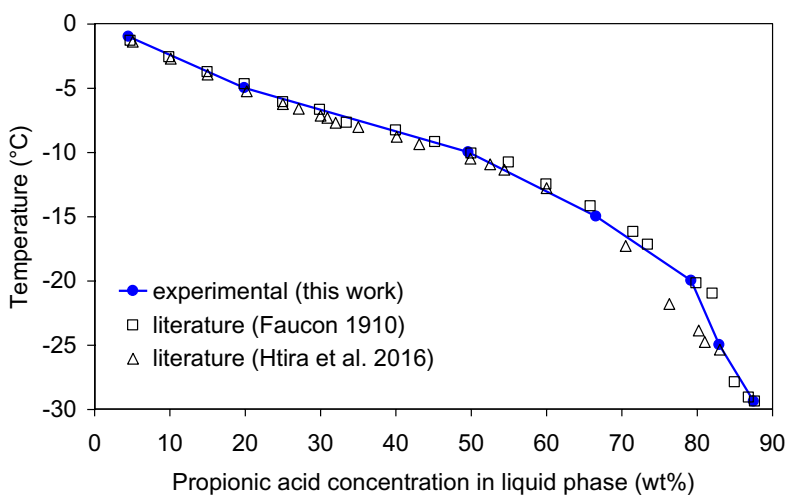

Fig. 3 Solid-liquid equilibrium concentration of propionic acid in water at different temperatures, showing experimental measurements (closed circle) and literature values (open square, open triangle) 


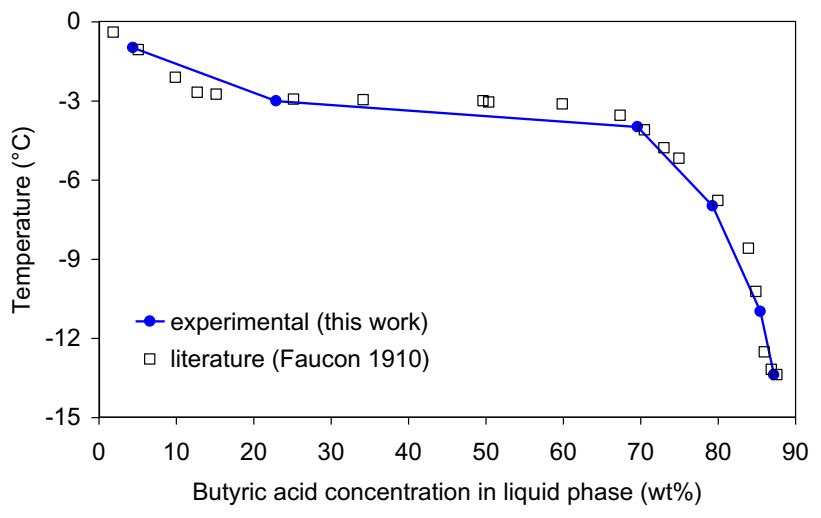

Fig. 4 Solid-liquid equilibrium concentration of butyric acid in water at different temperatures, showing experimental measurements (open circle) and literature values (open square)

$87.6 \mathrm{wt} \%$ found by Faucon [7]. As a consequence of the limited number of data points collected, some of the curvature of the solid-liquid equilibrium was not apparent from the data in this study.

Due to the potential value of the experimental solid-liquid equilibrium data recorded in this study for future engineering work, the numeric data obtained is also reported (Table 2).

\section{Fractional freezing of Fischer-Tropsch acid water}

A synthetic Fischer-Tropsch acid water was prepared with $0.70 \mathrm{wt} \%$ acetic acid, $0.15 \mathrm{wt} \%$ propionic acid and $0.15 \mathrm{wt} \%$ butyric acid in water, i.e., $1.0 \mathrm{wt} \%$ total carboxylic acids in water. This was representative of the composition of stream 11 in Fig. 1.

Although the procedure for determining the acid concentration in the liquid phase at solid-liquid equilibrium was analogous to that used for the binary mixtures, the analytical work associated with determining the amount of each

Table 2 Experimental solid-liquid equilibrium data collected in this study for the binary systems of acetic acid-water, propionic acidwater, and butyric acid water

\begin{tabular}{|c|c|c|c|c|c|}
\hline \multicolumn{2}{|c|}{ Acetic acid } & \multicolumn{2}{|c|}{ Propionic acid } & \multicolumn{2}{|c|}{ Butyric acid } \\
\hline$T\left({ }^{\circ} \mathrm{C}\right)$ & $x(\mathrm{~mol} / \mathrm{mol})$ & $T\left({ }^{\circ} \mathrm{C}\right)$ & $x(\mathrm{~mol} / \mathrm{mol})$ & $T\left({ }^{\circ} \mathrm{C}\right)$ & $x(\mathrm{~mol} / \mathrm{mol})$ \\
\hline-1.0 & 0.0079 & -1.0 & 0.011 & -1.0 & 0.0093 \\
\hline-5.0 & 0.050 & -5.0 & 0.057 & -3.0 & 0.057 \\
\hline-10.0 & 0.104 & -10.0 & 0.193 & -4.0 & 0.319 \\
\hline-15.0 & 0.161 & -15.0 & 0.326 & -7.0 & 0.439 \\
\hline-20.0 & 0.229 & -20.0 & 0.481 & -11.0 & 0.546 \\
\hline-25.0 & 0.285 & -25.0 & 0.541 & -13.4 & 0.583 \\
\hline-27.0 & 0.293 & -29.4 & 0.630 & & \\
\hline
\end{tabular}

$T$ temperature; $x$ mol fraction of acid in liquid phase at equilibrium carboxylic acid was more complex. Titration of the equilibrium solution would give the total carboxylic acid concentration, but not the relative concentration of the individual species. Concentration of individual acid species was determined using HPLC analysis.

The experimentally determined liquid phase concentration at solid-liquid equilibrium of the synthetic Fischer-Tropsch acid water is shown in Fig. 5.

The change in relative acid concentrations (Fig. 5) indicated that the solid phase was no longer pure water, as in the case for the solid-liquid equilibria of binary mixtures. The only way in which the relative concentration of the carboxylic acids in the liquid phase could change is if the solid phase also contained carboxylic acids. Thus, the data indicated that in a mixed carboxylic acid and water system, there was a partitioning of acids between the liquid and solid phases during fractional freezing. Considering the total acid concentration and the high relative amount of butyric acid in the liquid at low temperature (Fig. 5), acid inclusion in the solid phase was likely more prevalent at lower temperatures with more concentrated acid solutions.

To assess the impact of acid inclusion in the solid phase, the partitioning of the acids between the liquid and solid phase was determined experimentally. In each control experiment, the concentrated acid-water mixture was cooled to $-25{ }^{\circ} \mathrm{C}$, allowing around half of the acid water to freeze. The solid and liquid phases were separated, the solid phase was washed to remove acid solution on the outer surface, and material balance was performed on the washed solid, liquid obtained from washing and the liquid phase (Table 3).

The material balances on the individual acids were acceptable. The compositions of interest are those of the liquid phase and the solid phase shown in Table 3. The solid phase had a high acid concentration. The acid concentration

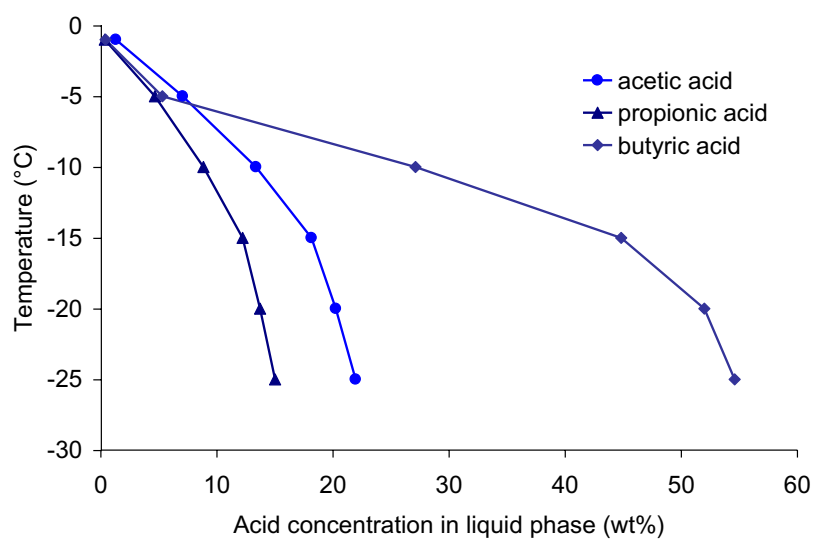

Fig. 5 Solid-liquid equilibrium concentration of synthetic FischerTropsch acid water at different temperatures, showing experimental measurements for acetic acid (open circle), propionic acid (closed triangle), and butyric acid (closed diamond). 
Table 3 Partitioning of carboxylic acids in a concentrated mixed carboxylic acid solution between liquid and solid phases at $-25^{\circ} \mathrm{C}$

\begin{tabular}{|c|c|c|c|c|c|c|}
\hline \multirow[t]{2}{*}{ Description } & \multicolumn{4}{|c|}{ Mass of material (g) } & \multirow[t]{2}{*}{ Total mass (g) } & \multirow[t]{2}{*}{ Acid fraction } \\
\hline & Acetic acid & Propionic acid & Butyric acid & Water & & \\
\hline \multicolumn{7}{|l|}{ Control experiment 1} \\
\hline Feed material prepared & 61.76 & 59.52 & 57.64 & 297.38 & 476.30 & 0.376 \\
\hline Liquid phase composition at $-25^{\circ} \mathrm{C}$ & 30.45 & 29.48 & 29.06 & 106.23 & 195.22 & 0.456 \\
\hline Solid phase composition at $-25^{\circ} \mathrm{C}$ & 10.52 & 10.03 & 9.67 & 55.13 & 85.36 & 0.354 \\
\hline Wash water ${ }^{\mathrm{a}}$ & 22.90 & 18.35 & 22.20 & 526.10 & 589.55 & 0.108 \\
\hline Material balance (product - feed) & 2.11 & -1.66 & 3.29 & - & - & - \\
\hline \multicolumn{7}{|l|}{ Control experiment 2} \\
\hline Feed material prepared & 80.99 & 57.27 & 97.92 & 263.82 & 500.00 & 0.472 \\
\hline Liquid phase composition at $-25^{\circ} \mathrm{C}$ & 40.19 & 29.23 & 48.90 & 113.96 & 232.27 & 0.509 \\
\hline Solid phase composition at $-25^{\circ} \mathrm{C}$ & 15.47 & 10.87 & 19.64 & 63.73 & 109.71 & 0.419 \\
\hline Wash water ${ }^{\mathrm{a}}$ & 23.06 & 17.53 & 28.26 & 426.33 & 495.18 & 0.139 \\
\hline Material balance (product - feed) & -2.28 & 0.37 & -1.13 & - & - & - \\
\hline
\end{tabular}

${ }^{a}$ The wash water was obtained by washing the solid phase with chilled water to remove the liquid adhering to the outside of the solids. The composition had to be determined and included for material balance purposes

in the solid phase was much higher than could be explained by the occlusion of some acid solution during freezing. The acid content in the solid phase was therefore present due to partitioning as a consequence of solid-liquid equilibrium.

The results indicated that acid partitioning between the liquid and solid phases was such that fractional freezing had poor selectivity (compare acid fractions in feed, liquid phase, and solid phase in Table 3) for concentrating a mixed acid solution at $-25^{\circ} \mathrm{C}$. Although these experiments were limited in scope, they experimentally confirmed what was indicated by results in Fig. 5, namely, that fractional freezing of mixed carboxylic acids in water did not form an acid-free solid phase.

\section{Discussion}

Binary carboxylic acid and water solid-liquid equilibrium data in literature $[7,9]$ showed that it was possible to increase the concentration of the carboxylic acids by fractional freezing. The solid-liquid equilibrium data were confirmed in this study (Figs. 2, 3, 4). For binary mixtures, it was possible to increase the acid concentration beyond $50 \%$ before the eutectic point was reached. Based on the binary solid-liquid equilibria, fractional freezing appeared to be a promising process (Fig. 1). It would not only produce a concentrated acid solution from which the acids could be efficiently recovered by distillation, but also produce a wastewater stream that would have a substantially reduced chemical oxygen demand for wastewater treating compared to the acid water.

Based on the binary solid-liquid equilibrium data, it was anticipated that a practical operating temperature for the first stage of fractional freezing would be around the range between 0 and $-5^{\circ} \mathrm{C}$, since this already led to an order of magnitude increase in acid concentration (Figs. 2, 3, 4). The mixed acid solid-liquid equilibrium data (Fig. 5) indicated that the first stage of fractional freezing is better operated between 0 and $-1{ }^{\circ} \mathrm{C}$. The solid phase initially separated contains water with a reduced acid content.

For a single equilibrium stage freezing step operated at $-1{ }^{\circ} \mathrm{C}$, more than half of the solution was converted to a solid, which would cause flow assurance problems for a practical design. The material balance indicated that the acetic acid concentration in the solid phase was $0.34 \mathrm{wt} \%$ (compared to $0.70 \mathrm{wt} \%$ in the feed), and the propionic acid concentration in the solid phase was $0.03 \mathrm{wt} \%$ (compared to $0.15 \mathrm{wt} \%$ in the feed). The partitioning of the carboxylic acids between solid and liquid was not very selective when so much solid material was formed in the first solid-liquid equilibrium stage. By controlling the duty to limit the extent of fractional freezing in each equilibrium stage (not temperature as was employed in this work), it is in principle possible to develop a practical engineering design.

From a practical point of view, it is better to limit the solid content of the slurry that develops on cooling to avoid issues with slurry pumping and operation of the continuous filtration system. A duty-controlled staged separation would have the added benefit of obtaining a cleaner wastewater product, reduce the amount of acid carryover with the ice, and reduce the extent of solid (ice) washing.

This study provided the initial work necessary to confirm solid-liquid equilibrium for binary carboxylic acid and water mixtures, as well as for a more realistic mixed carboxylic acid and water mixture. It indicated that much of separation is possible in the temperature range 0 to $-5^{\circ} \mathrm{C}$. It also 
indicated that the development of fractional freezing as a process would have to employ multiple solid-liquid equilibrium stages.

Additional experimental data are necessary in this temperature range to reliably determine the extent of carboxylic acid partitioning in the solid phase to assist with designing a realistic multi-stage solid-liquid separation system. Such additional work is also required to perform a credible techno-economic evaluation. The present study nevertheless provided useful solid-liquid equilibrium data and provided a framework that can be used for gathering duty-controlled fractional freezing data using actual Fischer-Tropsch acid water to enable process design.

\section{Conclusions}

Solid-liquid equilibrium data for binary mixtures of acetic acid and water, propionic acid and water, and butyric acid and water were collected. Reasonable agreement was found between the experimental solid-equilibrium data collected in this study and that reported in literature.

Processing Fischer-Tropsch acid water by fractional freezing was evaluated using a synthetic mixture of carboxylic acids in water. Although the quaternary mixture of acetic acid, propionic acid, butyric acid and water represented only the major components in an actual Fischer-Tropsch acid water stream, it was sufficiently complex to highlight the importance of exploiting the initial acid-water partitioning and the necessity of using multi-stage solid-liquid separation design. Based on the work presented, it was possible to propose a duty-controlled staged separation process and indicate what remaining data had to be collected to enable process design.

Acknowledgements Credit for the idea that led to this investigation must partly go to Jonathan P. Mathews (Pennsylvania State University) and the late Burtron H. Davis (University of Kentucky) following on a fruitful discussion in Edmonton, $\mathrm{AB}$, some years ago. Funding for this investigation was provided by the Helmholtz-Alberta Initiative (HAI) and Natural Resources Canada (NRCan) through an EcoETI grant.

Open Access This article is licensed under a Creative Commons Attribution 4.0 International License, which permits use, sharing, adaptation, distribution and reproduction in any medium or format, as long as you give appropriate credit to the original author(s) and the source, provide a link to the Creative Commons licence, and indicate if changes were made. The images or other third party material in this article are included in the article's Creative Commons licence, unless indicated otherwise in a credit line to the material. If material is not included in the article's Creative Commons licence and your intended use is not permitted by statutory regulation or exceeds the permitted use, you will need to obtain permission directly from the copyright holder. To view a copy of this licence, visit http://creativecommons.org/licenses/by/4.0/.

\section{References}

1. Ahad N, De Klerk A (2018) Fischer-Tropsch acid water processing by Kolbe electrolysis. Fuel 211:415-419

2. Chen H, Lee J, Zheng Y, Duan Q (2016) A non-traditional energy transfer process in CWPO heterogeneous reaction for wastewater treatment. Chem Eng Res Des 114:142-147

3. Collings J (2002) Mind over matter. The Sasol story: a half-century of technological innovation. Sasol, Johannesburg

4. Coronado I, Pitínová M, Karinen R, Reinikainen M, Puurunen RL, Lehtonen J (2018) Aqueous-phase reforming of Fischer-Tropsch alcohols over nickel-based catalysts to produce hydrogen: product distribution and reaction pathways. Appl Catal A 567:112-121

5. De Klerk A (2011) Fischer-Tropsch refining. Wiley, Weinheim

6. Dry ME (1987) Chemicals produced in a commercial FischerTropsch process. ACS Symp Ser 328:18-33

7. Faucon MA (1910) Recherches sur les mélanges d'eau et d'acides gras. (Engl. Transl. "Research on mixtures of water and fatty acids"). Ann Chim Phys (Paris) 8(19):70-152

8. Gao W, Smith DW, Habib M (2008) Petroleum refinery secondary effluent polishing using freezing processes-toxicity and organic contaminant removal. Water Environm Res 80:517-523

9. Htira T, Cogné C, Gagnière E, Mangin D (2016) Determination of the solid-liquid phase diagram of the binary system propionic acid/water. J Chem Eng Data 61:806-812

10. Liao X, Wang F, Wang Y, Cai Y, Liu H, Wang X, Zhu Y, Chen L, Yao Y, Hao Q (2020) Constructing Fe-based bi-MOFs for photocatalytic ozonation of organic pollutants in Fischer-Tropsch waste water. Appl Surf Sci 509:145378

11. Maitlis PM, De Klerk A (2013) Greener Fischer-Tropsch processes for fuels and feedstocks. Wiley-VCH, Weinheim

12. Poling BE, Prausnitz JM, O'Connell JP (2001) The properties of gases and liquids, 5th edn. McGraw-Hill, New York

13. Reyhanitash E, Brouwer T, Kersten SRA, Van der Ham AGJ, Schuur B (2018) Liquid-liquid extraction-based process concepts for recovery of carboxylic acids from aqueous streams evaluated for dilute streams. Chem Eng Res Des 137:510-533

14. Rodríguez M, Luque S, Alvarez JR, Coca J (2000) A comparative study of reverse osmosis and freeze concentration for the removal of valeric acid from wastewaters. Desalination 127:1-11

15. Wagner FS Jr (1978) Acetic acid. Kirk-Othmer encyclopedia of chemical technology, vol 1, 3rd edn. Wiley, New York, pp 124-147

Publisher's Note Springer Nature remains neutral with regard to jurisdictional claims in published maps and institutional affiliations. 